\title{
Factors Influencing The Intention to Adopt eWallet among Students of Universiti Putra Malaysia
}

\section{Syuhaily Osman, Leong Yun Yi}

To Link this Article: http://dx.doi.org/10.6007/IJARBSS/v11-i11/11650

DOI:10.6007/IJARBSS/v11-i11/11650

Received: 13 September 2021, Revised: 15 October 2021, Accepted: 30 October 2021

Published Online: 17 November 2021

In-Text Citation: (Osman \& Yi, 2021)

To Cite this Article: Osman, S., \& Yi, L. Y. (2021). Factors Influencing The Intention to Adopt eWallet among Students of Universiti Putra Malaysia. International Journal of Academic Research in Business and Social Sciences, 11(11), 1624-1641.

\section{Copyright: @ 2021 The Author(s)}

Published by Human Resource Management Academic Research Society (www.hrmars.com)

This article is published under the Creative Commons Attribution (CC BY 4.0) license. Anyone may reproduce, distribute, translate and create derivative works of this article (for both commercial and non0-commercial purposes), subject to full attribution to the original publication and authors. The full terms of this license may be seen at: http://creativecommons.org/licences/by/4.0/legalcode

Vol. 11, No. 11, 2021, Pg. $1624-1641$

Full Terms \& Conditions of access and use can be found at http://hrmars.com/index.php/pages/detail/publication-ethics 


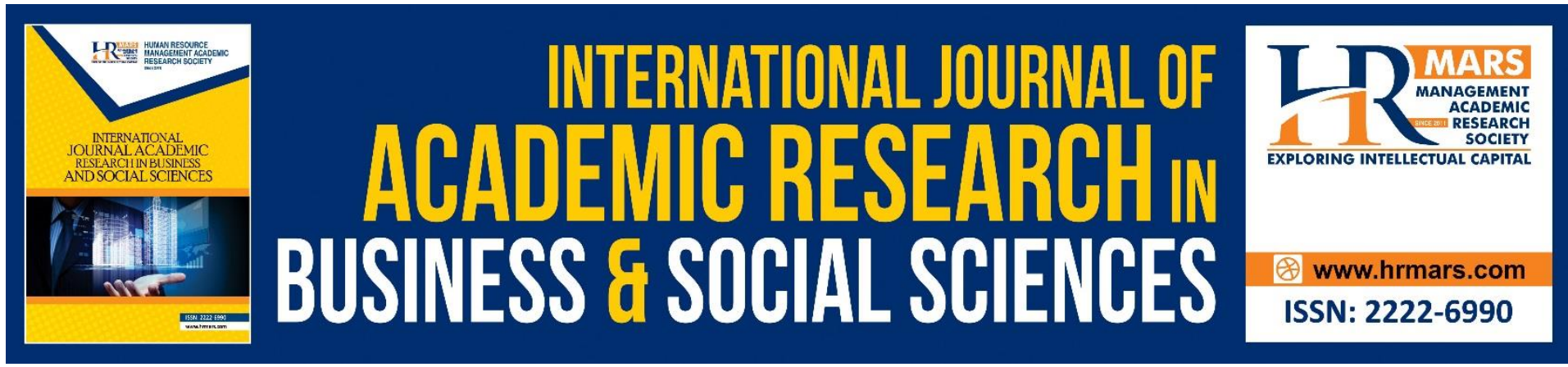

\title{
Factors Influencing The Intention to Adopt eWallet Among Students of Universiti Putra Malaysia
}

\author{
Syuhaily Osman, Leong Yun Yi \\ Sustainable Consumption Research Center of Excellence, Faculty of Human Ecology, \\ Universiti Putra Malaysia, 43400 Serdang, Selangor. \\ Email: syuly@upm.edu.my
}

\begin{abstract}
This research is aimed to investigate the factors influencing student's intention to adopt eWallet in Universiti Putra Malaysia. A total of 200 students from Universiti Putra Malaysia participated in this research where they were chosen through simple random sampling method and systematic sampling method. Data were collected through self-administered questionnaires. Categorical scale and five-point Likert scale were applied to analyze the background of respondents, as well as to measure the independent and dependent variables respectively. The findings form the Pearson Correlation analysis showed that UPM students' intention to adopt eWallet had positive relationship with perceived usefulness $(r=0.846$, $p=0.001)$, perceived ease of use $(r=0.773, p=0.001)$, perceived security $(r=0.397, p=0.001)$ and subjective norms $(r=0.528, p=0.001)$. Meanwhile, based on the results of multiple linear regression analysis, the model contributed a total of $77.1 \%$ and perceived usefulness appeared as the most significant factor that contributed to the intention to adopt eWallet among UPM students. Hence, the findings of this study were useful for eWallet companies and developers in providing better understanding about factors that influence consumers' intention to adopt eWallet in order to enhance their applications and fulfil what consumers really want.
\end{abstract}

Keywords: Perceived Usefulness, Perceived Ease of Use, Perceived Security, Subjective Norms, Ewallet

\section{Introduction}

Electronic wallet (eWallet) known as a software application that is installed on mobile phone. In order to initiate mobile payments, eWallet enables the access and storage of numerous payments credentials and top-up services for instance bank, prepaid, credit or debit card accounts, transit tickets, coupon and loyalty information. Nowadays, eWallet has become handy and convenient in high-volume and low-value situations for instance parking, transit, fast food restaurants and convenience stores. Moreover, providers also have merged with electronic coupons, loyalty rewards, location-based discounts and other promotional offers into eWallets in order to add value beyond payment functions (Tavilla, 2012). 
Wallet started gaining its popularity as one of the types of mobile payment option for transactions in Malaysia as consumers able to use eWallet to save the billing and shopping information that consumers can recall with one-click while shopping using their smartphone. Not only that, with all the cashless policies by Bank Negara Malaysia (BNM), the cash usage will reduce over time, and the adoption of mobile payments will grow. BNM regulate e-money as the digital money that gets stored in the eWallet and legally recognized as a valid and enforceable legal tender in Malaysia. There are 44 e-money licenses have BNM granted which are 5 banks and 39 non-banks (Bank Negara Malaysia, 2019).

According to Cheng, Cheong, Lee, Lim and Mok (2018), they pointed out that the new payment method, eWallet will facilitate the growth of e-commerce as it replaced the role of a traditional wallet. However, the intention to adopt eWallet in Malaysia was remained unclear due to limited research and responses received from users (Lim, 2018; Yapp, 2018). Tan and Cheong (2018) claimed that given the growing importance of eWallet, Malaysia currently still considered lags regional players given its low adoption compared to China, India and Singapore. Moreover, Malaysian were rarely engaged in eWallet because of several challenges for instance they have a few knowledges on internet and this lead less confident on the adoption of eWallet (Saxena, Vyas, Kumar \& Gupta, 2019). There are some consumers still insisted to apply the traditional payment types which are cash, debit card, credit card and cheques because there are doubtful with the advantages of eWallet (The Nielson Company, 2019).

In addition, consumers refused to adopt eWallet as they did not perceive the system setting to be useful and able to fulfil their expectation and requirement (Ellia, 2017). Consumers refused to use eWallet as they perceived that it was a waste of time to install and set up eWallet at the initial verification stage even though the eWallet companies hold the honor of being easier to use. Besides, consumers may perceive eWallet was not useful due to low merchant acceptance. According to The Nielson Company (2019), there were $27 \%$ of the consumers do not adopt eWallet due to low merchant acceptance at this infancy stage where the system was still unready.

On the other hand, people rejected to use eWallet as they perceived it was not easy to use. Nowadays, even though most of the Malaysian were using smart phones but they may be not familiar with eWallet especially those of aging population who required plenty of time to absorb information about the new technology (Ellia, 2017). Hence, features like conducting a transaction payment or top up value through eWallet might be a difficult and confuse task for a new user.

According to Central Bank of Malaysia (2019), customers reject to adopt eWallet due to lack of awareness towards eWallet's security features. Consumers rejected to use eWallet as they perceived there would be a high risk of security and privacy issues such as personal data being monitored or hacked, unsecured transactions as compared to credit and debit card transactions as well as the possible fraudulent charges (Tavilla, 2012). Some of the consumers' concerns may be based on misperception and misleading information about eWallet which hindered their intention to adopt. 
Besides, some of the Malaysian rarely engaged into eWallet because of low penetration and awareness of eWallet features among people. In fact, most of the Malaysian still conducted their payment by using the traditional payment method which were cash and cards. Aydin and Burnaz (2016) pointed out that lack impact in the influence of surrounding people on use intention to use eWallet had caused little responds from public in initial of life cycle.

In fact, there are several studies had been conducted to intention of young consumer towards the adoption of eWallet in different developing countries such as Indonesia (Varsha \& Thulasiram, 2016); India (Trivedi, 2016); China (Teng et al., 2018) and Vietnam (Cao et al., 2016). However, in Malaysia there were still a limited finding on the factors that influence universities' student to adopt eWallet in Malaysia. According to the Department of Statistics Malaysia (2019), the Malaysia population stood at 32.6 million people where 28.8 percent are young adults aged between 18 to 24 years old. Hence, universities' students will be a beneficial target segment for marketers due to the greater spending power owned by younger generation (Globe Newswire, 2012; Heller, 2015).

Moreover, most of the previous studies focus on technical design, security adoption, diffusion, and understanding user motivations (Olsen, Hedman \& Vatrapu, 2012). Hence, this is worthy to investigate the factors that influence the intention to adopt eWallet among students in Universiti Putra Malaysia as most of studies foresee that adoption of eWallet will increase significantly in the coming few years.

\section{Literature Review}

Till now, ample of studies had been conducted to investigate factors affecting the intention to eWallet adoption by using different models and theory. Example of these theories are Theory of Reasoned Action (TRA - Fishbein and Ajzen, 1975), Theory of Planned Behaviour (TPB Ajzen, 1991), Social Cognitive Theory (SCT - Bandura, 1986), Innovation Diffusion Theory (IDT - Rogers, 1995), Technology Acceptance Model (TAM - Davis, 1989), and Unified Theory of UTAUT 2 is originated from UTAUT model. The UTAUT is developed by Venkatesh, Morish, Davis and Davis, in 2003. This model is captured from eight competing models which are TRA, TAM, IDT, motivational model, theory of planned behaviour, model combining the technology acceptance model and theory of planned behaviour, model of PC utilization, and social cognitive theory.

In 2012, Ventakesh develops and enriches UTAUT model into UTAUT 2 model in which UTAUT 2 model is very appropriate to study adoption in technology which is directly related to consumer products. Venkatesh, Thong, and Xu (2012) identify three key constructs which explain the consumer's behaviour in the use of technology: hedonic motivation, price value and habit and they propose gender, age and experience as moderator variables in their model. Thus, the UTAUT2 model presents seven constructs (performance expectancy, effort expectancy, social influence, facilitating conditions, hedonic motivation, price value, and habit) as determinants of behavioural intention or use of a technology by consumers.

Comparing results from UTAUT2 and UTAUT, Venkatesh et al (2012) find out how the variance explained in both behavioral intention (74\%) and technology use (52\%) are substantial, compared to the baseline UTAUT that explained 56 percent and 40 percent of the variance in intention and use respectively (Arenas- Gaitán et al., 2015). UTAUT 2 model is used in this 
study because the model synthesis of eight previous acceptance of technology theory which has been updated, thus it is expected to provide clearer understanding of factors determining behavioural intention to adopt eWallet.

Numerous antecedent variables were applied to predict the adoption of technology in previous studies in which they have found that among the factors were perceived usefulness (Yang et al., 2021; Intarot, 2018; Shankar \& Datta, 2018; Mun et al., 2017; Sidek, 2015; Akturan \& Tezcan, 2012), perceived ease of use (Yang et al., 2021; Chawla \& Joshi, 2020; Grover, Kar, \& Janssen, 2019; Ilavarasan Mehrad \& Mohammadi, 2017; Roy \& Sinha, 2017; Trivedi, 2016), perceived security (Wong \& Mo, 2019; Batra \& Kalra, 2016; Varsha \& Thulasiram, 2016; Liu et al., 2012) and subjective norms (Sarika \& Vasantha, 2019; Lwoga \& Lwoga, 2017; Cao, et al., 2016; Oliveira et al., 2016; Amoroso \& Magnier, 2012).

Perceived usefulness is known as the extent to which applying a technology will give benefits in performing particular activities from the point of view of consumers (Lwoga \& Lwoga, 2017; Venkatesh et al., 2012). According to Murthy and Mani (2013), if a technology is not perceived to be useful, it is not likely to be adopted regardless of its attentive implementation efforts while perceived usefulness may vary across each person. Therefore, this variable has been explored in many studies with regards to technology adoption. For example, Akturan and Tezcan (2012) conducted a study to determine the mobile banking adoption of the youth market in Turkey and they found that perceived usefulness was determined to be the most important in determining the consumers' intention.

In Teng et al.'s (2018) study, perceived usefulness was also found to be positively influenced customers' intention to adopt eWallet services in Nanjing, China. This finding implied that mobile users intended to adopt eWallet due to its convenience as compared to traditional payment methods in term of portability since the users able to conduct their daily payment activities without carry along a physical wallet. In similar vein, respondents in Bradford and Hayashi's (2014) study also claimed that eWallet has reduced the inconvenience of bringing a stack of credit cards as eWallet enable the users to link their credit cards to the phone. While in Malaysian's context, Sidek (2015) has discovered that the young consumers in Malaysia, regardless of gender, education level or usage experience has showed a strong perceived usefulness toward the adoption of eWallet as they find eWallet to be a timesaving tool.

By referring to the previous findings, perceived usefulness is concluded as playing a significant role in the behavioral intention of individual to adopt eWallet. Thus, it is proposed that:

$\mathrm{H}_{1}$ : Perceived usefulness has a significant influence on intention to adopt eWallet among UPM students.

Pertaining to perceived ease of use, it is a measurement of how easy the product or service is to apply by its intended users (Davis, 1989). It is also stated as the extent to which an individual think that applying a technology would be effortless. Hence, due to the nature of eWallet which needs a level of knowledge and skill, perceived ease of use could play an important role to determine the intention to adopt eWallet. Perceived ease of use would significantly and positively influence consumers' intention to adopt eWallet and it can be seen from several previous researches, such as Yang et al. (2021); Chawla and Joshi (2020); Grover et al (2019); Pal, Vanijja, and Papasratorn (2015); Sidek (2015); Seetharaman et al (2017). Besides, people 
will believe that eWallet usage is helpful if it could be learned easily (Mehrad and Mohammadi, 2017). Hence, the findings of these researches showed that individuals who perceive the eWallet to be easy to use in their daily activities will most likely to adopt it.

Sidek (2015) found that majority of the male users in Malaysia regardless of age, education level or usage experience tended to stay positive and confidence when exposing to a new technology such as eWallet. Likewise, the study also found that most of the male users were early adopters as they perceived the new technology, eWallet to be easy to use. In contrast, unlike early adopters, the late adopters only willing to adopt a new technology when it has matured and has been adopted by many no matter how easy the eWallet could be (Teo \& Ranganathan, 2004).

Consumers will be intended to adopt any new technology if less effort was required. Even though most people were acquainted with using smart phones, but they may be new to some mobile applications. Eventually, features like conducting a transaction payment through a mobile application might be a difficult and confuse task for a new user. Hence, if eWallet is simple and effortless, it will generate a large impact towards the acceptance of eWallet (Sunny \& George, 2018). Aydin and Burnaz (2016) also found that if eWallet is embedded with userfriendly designs and interfaces, it would match users' expectation to conduct it effortlessly. Users perceived that they would adopt eWallet if the procedures were simple to conduct with least efforts. This finding also supported by Tu (2019) as difficulties in applying eWallet would become hindrance as consumers may be impatient with it. Based on the previous findings discussed above, this study proposed that:

$\mathrm{H}_{2}$ : Perceived ease of use has a significant influence on intention to adopt eWallet among UPM students.

This current study also focus on how the security of eWallet application can influence the intention to adopt. Shin (2009) stated that perceived security is the extent to which a person believes that using a fixed mobile payment procedure will be secure. Meanwhile, according to Suh and Han (2003), the concerns towards security are known as authentication (data exchange only involved restricted legitimate user during the transaction), confidentiality (data exchanged only can read and understood by intended users during the transaction), nonrepudiation (participants of the transaction incapable to deny their participation in the transaction), and data integrity (accurate data exchanged during the transactions).

A study on the behavioural intention of young consumers towards eWallet adoption among Indonesian users were conducted by (Varsha and Thulasiram, 2016). Based on the study, perceived security was identified as the most dominant factor for the intention of eWallet adoption among Indonesian young consumers. Batra and Kalra (2016) found that the major concern of the undergraduate students in India were the safety of money transaction. The respondents perceived the eWallet system was more safe and secure as compared to traditional payment method and they showed their positive intend to adopt. Hence, this indicated that strengthen in eWallet's security will increase the consumers' intention to adopt it. Additionally, Taheam, Sharma and Goswami (2016) proposed that the youth in Punjab perceived security is their most concerns when using eWallet as it could enhanced the individual performance of consumers. 
However, Teoh et al (2013) pointed out that the users in Malaysia perceived security do not significant associated with consumers' perception toward e-payment. Most of the users showed their negative intend to adopt e-payment as they perceived there would be a high risk of security and privacy issues such as personal data being monitored or hacked, unsecured transactions as compared to credit and debit card transactions as well as the possible fraudulent charges. Due to inconsistency of findings with regards to this variable of perceived security in determining the technology adoptions, this current study is intent to further examine it in undergraduate students' context. However, it is still proposed that:

$\mathrm{H}_{3}$ : Perceived security has a significant influence on intention to adopt eWallet among UPM students.

Furthermore, due to the beliefs that consumers' reference groups through the reviews from previous experts, influences by mass media, family members, friend and relatives will also influence their technology adoption, this current study is also intent to examine this factor as well. Ajzen (2008) defined subjective norms as the perceived social pressure directed from surroundings that caused an individual either to practise a specific behaviour or not. Karjaluoto et al (2010) stated that subjective norms is the extent where an individual's decisions to apply a product or a service is influenced by the suggestions from their socialising agents for instance parents, relatives, friends, and colleagues.

Many previous studies have found that subjective norms is one of the influential factors in technology adoptions For example, in Amoroso and Magnier's (2012) study, it indicated that subjective norms shows a significant positive relationship towards the adoption of eWallet in Japan as consumer think that most people believe that they should apply a designated new technology. In a more recent study by Slade, Dwivedi, Piercy and Williams (2015), they found that subjective norms is the most concern toward the intention to adopt e-payment by nonusers. The finding was further supported by Cao et al (2016) as they claimed that subjective norms had significant influence towards the intention use eWallet among the consumers in Vietnam due to high penetration of eWallet benefits by people surrounded.

However, a study conducted by Trivedi (2016) stated that subjective norms do not have positive significant influence on young adults' intention to adopt eWallet in India compared to other factors. The finding of the study was corresponded to Aydin and Burnaz (2016) where subjective norms was stated to have no significant influence between group mainly due to lower penetration and awareness of mobile payment system among people in Turkey as most of the people in Turkey still conducted their payment by using the traditional payment method.

Based on all the previous studies, it can be concluded that inconsistencies finding about subjective norms in different settings. Therefore, there is a need to examine this construct towards behavioural intention of eWallet adoption among university students as well. Along this vein, the following hypothesis was constructed:

$\mathrm{H}_{4}$ : Subjective norms has a significant influence on intention to adopt eWallet among UPM students. 


\section{Methodology}

In this study, quantitative method was applied to test theory and generalised a conclusion or findings (Wright et al., 2016). Quantitative method was applied to study the relationship between variables as to examine the relationship between the factors and intention to adopt eWallet in numerical through analysis. Moreover, descriptive design was applied in designing a structured questionnaire and this method used to describe and interpret phenomena of behavioural intention to practice retail transaction with eWallet is through survey method where conducting survey was the only way of research to collect information from target audiences (Dulock, 1993). Descriptive design had applied as it can produced more productive data and information about the factors that influence the intention to adopt eWallet among students in UPM that leaded to important suggestion in reality or further research (Labaree, 2009).

The location that was chosen in this study was at Universiti Putra Malaysia (UPM), Serdang, Selangor Darul Ehsan. First, based on the latest report of MCMC, Selangor state was chosen due to it has the second highest mobile penetration of $138.3 \%$ (Hand Phone Users Survey, 2019). Besides, UPM also covers the students who have the intention to adopt eWallet as well as these targeted respondents were using smart phones from an early age and they are interested in new advanced technologies (Chris, 2019). Besides, undergraduate students who represented as the younger generation were potential customers of eWallet due to high spending power (Globe Newswire, 2012; Heller, 2015). In this study, simple random sampling was applied to choose four faculties out of 16 faculties in UPM. Four faculties were involved due to the reason of obtaining the total sample size that has been determined, four faculties are more manageable and good enough to represent UPM's student population. This study divided the faculties into two group which were science-based faculties and social sciencebased faculties. Four faculties were randomly selected from these two groups of faculties by using lottery method of sampling. Based on the lottery method of sampling, four number had been randomly picked with each number corresponding to the respective faculties. Hence, Faculty of Science, Faculty of Computer Science and Technology, Faculty of Economics and Management and Faculty of Human Ecology were chosen to represent the science-based faculty and social science-based faculty respectively. Next, systematic sampling was applied in this study as it was a method in which respondents from a larger population were chosen according to a random starting point with a fixed sampling interval. Hence, in this study, systematic sampling was applied to select every $4^{\text {th }}$ student who passed by the main entrance of the selected faculties.

The present study consisted sample size of 200 respondents in UPM who were at the age of 18 and above. According to Gorsuch (1974), sample size lower than 50 is considered as small sample size, on the other hand, sample size of 200 is considered as large. This statement supported by Guilford (1954) who said that a minimum sample size of 200 is considered as proper for a research. A self-administered questionnaire was used as the instrument to collect the study data. It was comprised of 25 questions in total and the survey questionnaire was separated into two main sections. In section $A$, the questions were mainly related to basic information of the respondents which were age, gender, ethnic, faculty and classification of bachelor's degree. Meanwhile, Section B included 25 questions, 5 questions would be tested for dependent variable which was intention to adopt eWallet while the other 20 questions 
were related to the other four independent variables which were perceived usefulness, perceived ease of use, perceived security and subjective norms respectively.

The measurements for all the main variables understudy were adapted from previous studies. This scale for intention to adopt eWallet were adapted from Venkatesh and Davis 2000 as well as Manikandan and Jayakodi (2017). Meanwhile, the scale items adopted from Bhattacherjee (2001) were used in measuring perceived usefulness, Venkatesh and Davis (2000) for perceived ease of use, Liu and Tai (2016); Taheam et al (2016); Davis, Balaji and Gurusamy (2017) for perceived security and Lu, Yao and Yu (2005) as well as Koening, Marquet, Palmer and Zhao (2015) for subjective norms. These items were measured using a 5-point Likert scale, ranging from "strongly disagree" to "strongly agree". All the measurements were proved to have a high good reliability by using Cronbach alpha test in which they were obtained above 0.8 (intention to adopt $=0.875$; perceived usefulness $=0.897$; perceived ease of use $=0.885$; perceived security $=0.961$; and subjective norms $=0.948$ ).

The data collected were analyzed by using Statistical Package for Social Science (SPSS). Particularly, Pearson correlation analysis was used to examine the relationship between each factor influencing the intention to adopt eWallet. Also, multiple regression analysis was used to determine the most significant predictor that influence the intention to adopt eWallet.

\section{Findings and Discussion}

In terms of the background of respondents of this study, 38.5\% of respondents were male and $61.5 \%$ were female and the age of the respondents were ranged from 19 years old to 26 years old. UPM students with the age of 23 years old consisted the highest percentage which comprise $30.5 \%$ of respondents (30.5\%) whereas respondents with the age of 26 years old revealed the lowest percentage which only consisted of 1 person (0.5\%). Meanwhile, there were $43.5 \%$ of Muslim, $38.5 \%$ of Chinese, $14.0 \%$ of Indian and $4.0 \%$ of respondents from other ethnic involved in this study. A total of 200 respondents were chosen in the study, controlling the faculty factor (Faculty of Computer Science and Technology, Faculty of Economics and Management, Faculty of Human Ecology and Faculty of Science) with each factor approximately $25 \%$ of the respondents. In the aspect of the classification of bachelor's degree, statistics has shown that more than one-quarter of the respondents were fell into sophomore $(27.5 \%)$ and senior (36.0\%).

Based on the findings from the descriptive analyses for all the variables understudy, the intention to adopt eWallet among UPM students was considered high as the mean score was 4.00. This may be due to the eWallet services launched by providers was relevant and satisfied the needs of UPM students. The output was in parallel vein with the studies done by Madan and Yadav (2016), they found that youth in developing countries showed a positive intention towards the adoption of eWallet. Furthermore, UPM students' perceived usefulness towards the intention to adopt eWallet obtained the mean score of 3.86, which was considered as high. In agreement with Teng et al. (2018), they pointed out that perceived usefulness will positively influence customers' intention to adopt eWallet services in Nanjing, China. Therefore, majority of the respondents believed that perceived usefulness was one of the factors which led them to adopt eWallet. 
For the level of perceived ease of use, the descriptive analysis also found that it can be considered as to be in high level as well with the mean score of 3.75. This result indicated that most of the respondents believed that perceived ease of use was one of the factors which influenced them to adopt eWallet and this claim was supported by Pal et al (2015); Sidek (2015); Seetharaman et al (2017) as well as Mehrad and Mohammadi (2017) in which their studies concluded that individuals who perceive the eWallet to be easy to use in their daily activities were most likely to adopt it.

On the other hand, the result showed that UPM students' perceived security towards the intention to adopt eWallet and the influence of subjective norms were considered moderate as the mean score were 3.00 and 3.28, respectively. This could be supported by the research of Patel (2016) as most of the respondents perceived the security of eWallet was one of the concerns by respondents and the security systems of eWallet must strengthened so that consumers felt secure to adopt. Besides, Rai, Ashok, Chakraborty, Arolker and Gajera (2012) discovered that safety and security of payment as compared to traditional methods will influence consumers' intention to adopt eWallet.

However, in examining the significant influence of the factors on the intention to adopt eWallet, subsequent analysis by using inferential results from Pearson correlation test are much more needed. Therefore, the following discussion will be made for the hypotheses test results based on this analysis.

\section{Relationship between Factors and Intention Level to Adopt EWallet}

The results for Pearson correlation were summarized in Table 1, showing that all factors have positive $r$-value which indicated all the factors has positive linear relationship with intention to adopt eWallet. All these shown that all the hypotheses are supported. Perceived usefulness was found to has the strongest relationship $(r=0.846 ; p=0.001)$ with intention to adopt eWallet while comparing with the other factors. This suggested that the degree of usefulness is strongly associated with the intention to adopt. It is also indicated that the higher the perceived usefulness, the higher the intention to adopt eWallet among UPM students. The finding strengthened the study of Teng et al. (2018) in which they found that perceived usefulness would positively influence customers' intention to adopt eWallet services due to its convenience as compared to traditional payment methods.

Perceived ease of use is reported to have the second highest strength relationship with intention level to adopt eWallet. The r-value of $0.773(p=0.001)$ indicated that this factor was having a strong and positive relationship with the intention to adopt. Owing to this as well, the current finding corresponded to the prior research conducted by Aydin and Burnaz (2016) in which if eWallet is embedded with user-friendly designs and interfaces, it would match users' expectation to conduct it effortlessly.

In addition, the results of subjective norms $(r=0.528 ; p=0.001)$ and perceived security $(r=$ $0.397 ; p=0.001$ ) are a less explicit compared to the others two factors discussed earlier, with the latter is found to have the least (in terms of the strength) relationship with intention to adopt eWallet. However, the strength of the relationship was considered moderate as the $r$ value was in between 0.3 to 0.5 . This could be explained by the moderate willingness of UPM students to adopt eWallet as some of them perceived it to be secure. The finding strengthened 
the study of Taheam et al (2016) in which perceived security can influence people to adopt eWallet as mobile payment procedure was secure to be used. Meanwhile for subjective norms, the strength of the relationship can still be considered as strong as the value of correlation coefficient was greater than 0.5. Nonetheless, the current finding seems consistent with the previous research done by Cao et al (2016), an individual's decisions to adopt eWallet is influenced by the suggestions from subjective norms.

Table 1: Results of Pearson Correlation Coefficient

\begin{tabular}{lcc}
\hline \multicolumn{1}{c}{ Hypotheses } & $\begin{array}{c}\text { Pearson } \\
\text { Correlation } \\
\text { (r-value) }\end{array}$ & $\begin{array}{c}\text { Significance } \\
\text { level } \\
\text { (p-value) }\end{array}$ \\
\hline $\mathrm{H}_{1}: \begin{array}{c}\text { There is a significant relationship between the perceived } \\
\text { usefulness and the intention level to adopt eWallet among } \\
\text { UPM students. }\end{array}$ & $0.846^{* * *}$ & 0.001 \\
$\mathrm{H}_{2}:$ The is a significant relationship between the perceived ease \\
$\begin{array}{l}\text { of use and the intention level to adopt eWallet among UPM } \\
\text { students. }\end{array}$
\end{tabular}

Note: ${ }^{* * *} p \leq 0.001$

Subsequently, multiple regression analysis was conducted to determine the most dominant factor that influence the intention level to adopt eWallet among UPM students. Based on the result from multiple linear regression analysis in Table 2 , when all variables putting into a model and interact, effects are encountered. The regression model was statistically significant due to F-ratio value of 163.88 with a significant level of 0.001 , which is below 0.01 . This implied that, there was a statistically significant difference between the dependent variable (intention to adopt e--wallet) and independent variables (perceived usefulness, perceived ease of use, perceived security and subjective norms). Therefore, the overall model is significant and the fitness of the model is considered high.

Nonetheless, the result also indicated that the proportional contribution of the four factors to the intention to adopt eWallet was high (0.771) with an adjusted R-square $\left(\Delta R^{2}\right)$ of 0.766 . These statistics indicated that the four factors were able to predict up to $77.1 \%$ of the factors to the intention to adopt eWallet. According to Cohen (1988), R-square value which is more than 0.26 was meant for large effect size of predictors to the dependent variable. However, even though the four factors able to predict a high percent of the result, but the remaining $22.9 \%$ of the model was explained by also other factors that able to contribute in influencing the intention to adopt eWallet among UPM students.

The results also unveiled that perceived usefulness $(\beta=0.612, p=0.001)$, perceived ease of use $(\beta=0.364, p=0.001)$ and subjective norms $(\beta=0.041, p=0.001)$ were found as the significant 
predictors toward the intention to adopt eWallet among UPM students. However, the subjective norms, turned out to show non-significant relationship towards the intention to adopt eWallet ( $\beta=0.041, p=0.467)$. This could be justified that the subjective norms will not effectively influence UPM students to adopt eWallet. Even though subjective norms did not show a significant relationship towards the intention to adopt eWallet but perceived usefulness and perceived ease of use had significant relationship.

Among all the variables, perceived usefulness was found to be greatest influencing factor towards the intention to adopt eWallet among UPM students since it had highest regression coefficient ( $\beta=0.612$ ). There were several past studies that showed perceived usefulness is the most significant factor that directly influence the intention level to adopt eWallet (Mun et al., 2017; Sidek, 2015; Toh et al., 2009). In addition, perceived security $(\beta=-0.126, p=0.001)$ indicated that every 1 unit increase in perceived security, the intention to adopt eWallet among UPM students will decrease by 0.126 units. This could be justified that subjective norms had a direct effect on the intention to adopt among undergraduate students, but it was not the most significant factors that influencing the intention to adopt eWallet in a direct way.

Table 2: Summary of Multiple Linear Regression for Intention to Adopt EWallet among UPM Students

\begin{tabular}{lccc}
\hline Variables & $\begin{array}{c}\text { Standardized Coefficients } \\
\text { Beta }(\boldsymbol{\beta})\end{array}$ & Beta $(\mathbf{t})$ & p-value \\
\hline (Constant) & & $4.252^{* * *}$ & 0.001 \\
Perceived usefulness & 0.612 & $11.887^{* * *}$ & 0.001 \\
Perceived ease of use & 0.364 & $5.652^{* * *}$ & 0.001 \\
Perceived security & -0.126 & $-2.591^{* * *}$ & 0.001 \\
Subjective norms & 0.041 & 0.729 & 0.467 \\
\hline
\end{tabular}

Note: Dependent Variable $=$ Intention to adopt eWallet

$F=163.88, p<0.001, \mathrm{R}^{2}=0.771, \Delta \mathrm{R}^{2}=0.766$

${ }^{* * *} p<0.001$

\section{Implications and Conclusion}

Despite the rapid growth potential of eWallet and its ongoing interest in Malaysia, there is still lack of understanding concerning the characteristics of eWallet users in Malaysia and its potential impact on consumer marketing. This is mainly due to the fact that eWallet is still new in Malaysia and just beginning to take its place as an alternative payment method for consumers to pay for their goods and services. Hence, the findings of this study were useful for eWallet companies and developers to provide insight for better understanding about factors that influencing consumers' intention to adopt eWallet in order to enhance their applications and fulfil what consumers really want. The current findings could help eWallet company to understand consumers' preferences and construct marketing strategies that were effective to promote their application with good reputation.

Secondly, perceived usefulness and perceived ease of use were determined to have strong influence as compared to other independent variables in influencing UPM students' intention 
to adopt eWallet. Based on this study, it stated that the more likely one would perceive eWallet as useful and easy to use, the more likely one intends to use eWallet. Hence, eWallet application developer may focus on further innovation and convenience factors to enhance consumers perception such as the speed of payment transaction, time and effort to set up and learn to apply or even merchants' accessibility.

Thirdly, factor of perceived security was important in determining consumers' intention to adopt eWallet. However, misperception about the security of eWallet had hindered consumers from embarking into eWallet. Thus, in order to decrease this misperception and strengthen consumers' confidence on eWallet, related authorities such as retailers and businesses, financial institutions and government may deliver information relating to eWallet's security features positively and accurately to its users through educating and creating awareness about cyber security, eWallet fraud data and actions taken to combat eWallet fraud incidences.

Next, the impact of subjective norms should not be overlooked as the youth in Malaysia nowadays tend to follow trend as they always follow their favoured social influencers' opinions on media social. Furthermore, it also pointed out that the more people (families, friends or other consumers) are using eWallet, the more likely one would intend to adopt. Thus, marketing team in eWallet companies may think of the way to encourage consumers who are adopting eWallet to persuade others who are not using eWallet yet, for instance by providing them rewards for inviting friends to download and use.

As this study was designed to identify factors that influencing the intention to adopt eWallet among UPM students, it provided an exploratory examination of the relationship between perceived usefulness, perceived ease of use, perceived security, subjective norms and the intention to adopt eWallet. Based on the findings, there was a significant relationship between perceived usefulness, perceived ease of use, perceived security, subjective norms and the intention to adopt eWallet. Besides, majority of the UPM students positively intend to adopt eWallet towards the four of the examined factors especially perceived usefulness. However, when all the factors examined simultaneously, besides subjective norms, UPM students also showed undesirable intention towards perceived security as compared to other factors. According to The Nelson Company Malaysia Report (2019), there were $46 \%$ off non-users claimed that security concerns were their biggest barrier to adopt eWallet as they worried about the leakage of private information, bank details and money can be stolen by the scammers. Thus, this concern may cause UPM students. Thus, this may cause UPM students unlikely to adopt eWallet.

\section{References}

Ajzen, I. (1991). The theory of planned behaviour. Organizational Behavior and Human Decision Processes, 50(2), 179-219.

Ajzen, I. (2008). Consumer attitudes and behavior. Handbook of Consumer Psychology, 1, 525548.

Akturan, U., \& Tezcan, N. (2012). Mobile banking adoption of the youth market: Perceptions and intentions. Marketing Intelligence and Planning, 30(4), 444-459. 
Amoroso, D. L., \& Magnier, W. R. (2012). Building a research model for mobile wallet consumer adoption: The case of mobile Suica in Japan. Journal of Theoretical and Applied Electronic Commerce Research, 7(1), 94-110.

Arenas-Gaitán, J., Peral -Peral, B., \& Ramón -Jerónimo, M. A. (2015). Elderly and internet banking: An application of UTAUT2. Journal of Internet Banking and Commerce, 20(1), 1-23. https://doi.org/10.1007/978-3-531-92534-9_12

Aydin, G., \& Burnaz, S. (2016). Adoption of mobile payment systems: A study on mobile wallets. Journal of Business, Economics and Finance, 5(1), 73-92. Retrieved from: https://www.researchgate.net/publication/299407937_Adoption_of_mobile_ payment_systems_a_study_on_mobile_wallets

Bandura, A. (1986). Social foundations of thought and action: A social cognitive theory. Englewood Cliffs, NJ: Prentice- Hall, Inc.

Bank Negara Malaysia. (2019). List of regulatees. Retrieved from http://www.bnm.gov.my/index.php?ch=ps\&pg=ps_regulatees

Batra, R., \& Kalra, N. (2016). Are digital wallets the new currency?. Apeejay Journal of Management and Technology, 11(1), 1-12.

Bhattacherjee, A. (2001). Understanding information systems continuance: An expectationconfirmation model. MIS Quarterly, 25(3), 351-370.

Bradford, T., \& Hayashi, F. (2014). Mobile payments: Merchants' perspectives. Economic Review, Federal Reserve Bank of Kansas City, issue Q II, pages 33-58.

Cao, T. K., Dang, P. L., \& Nguyen, H. A. (2016). Predicting consumer intention to use mobile payment services: Empirical evidence from Vietnam. International Journal of Marketing Studies, 8(1), 117-124.

Central Bank of Malaysia. (2019). Payment and settlement systems report 2019. Retrieved from https://www.bnm.gov.my/files/publication/fsps/en/2019/cp04.pdf

Chandra, S., \& Kumar, K. N. Exploring factors influencing organizational adoption of augmented reality in ecommerce: Empirical analysis using technology-organizationenvironment model. Journal of Electronic Commerce Research, 19, 237-265.

Chawla, D., \& Joshi, H. (2020). Role of mediator in examining the influence of antecedents of mobile wallet adoption on attitude and intention. Global Business Review. https://doi.org/10.1177/0972150920924506

Cheng, S. W., Cheong, M., Lee, J. Y., Lim, J. T., \& Mok, W, K. (2018). Curbs on modern technology: Barriers of resistance towards eWallet in Malaysia. Retrieved from http://eprints.utar.edu.my/3073/1/fyp_AC_2018_CSW.pdf

Chris, N. (2019). How a young generation accepts technology. Retrieved from http://atechnologysociety.co.uk/how_young_generation_accepts_technology

Cohen, J. (1988). Statistical power analysis for the behavioral sciences (2nd ed.). Hillsdale, NJ: Erlbaum

Davis, F. D. (1989). Perceived usefulness, perceived ease of use, and user acceptance of information technology. MIS Quarterly, 319-340.

Davis, K. J., Balaji, P., \& Gurusamy, S. (2017). Whether eWallets are really a catalyst towards expedition of cashless economy?: An empirical investigation in the aftermath of demonetization. IOSR Journal of Business and Management, 1, 50-55.

Department of Statistics Malaysia. (2019). Current population estimates, Malaysia, 20172018. Retrieved from https://www.dosm.gov.my/v1/index.php?r=column/pdfPrev\&id=c1pqTnFjb29HSnNYN UpiTmNWZHArdz09 
Dulock, H. L. (1993). Research design: Descriptive research. Journal of Pediatric Oncology Nursing, 10(4), 154-157.

Ellia, P. (2017). How cashless is Malaysia right now? Retrieved from https://fintechnews.my/19964/payments-remittance-malaysia/cashless-malay siacredit-debit-card-e-wallet-money/

Fishbein, M., \& Ajzen, I. (1975). Belief, Attitude, Intention and Behavior: An Introduction to Theory and Research. Reading, MA: Addison-Wesley.

Globe Newswire. (2012). Campus life back in session: College students arrive confident, smarter and with climbing consumer spending power. Retrieved from https://globenewswire.com/news-release/2012/09/12/490387/10004857/en/ Campus-LifeBack-in-Session-College-Students-Arrive-Confident-Smart-erandWithClimbing Consumer-Spending-Power.html

Gorsuch, R. L. (1974). Factor Analysis. Philadelphia, Penn: Saunders.

Grover, P., Kar, A. K., Janssen, M., \& Ilavarasan, P. V. (2019). Perceived usefulness, ease of use and user acceptance of blockchain technology for digital transactions: Insights from user-generated content on Twitter. Enterprise Information Systems, 13, 771-800.

Guilford, J. P. (1954). Psychometric Methods. New York: McGraw-Hill.

Hand Phone Users Survey, (2019). Kajian Pengguna Mudah Alih. Malaysian Communications and Multimedia Commission.

https://www.mcmc.gov.my/ms/resources/statistics/hand-phone-surveys

Heller, L. (2015). Move over Millennials, Generation $Z$ is in charge. Retrieved from www.forbes.com/sites/lauraheller/2015/08/14/move-over-millennials-generationz-isin-charge/

Intarot, P. (2018). Influencing factor in eWallet acceptant and use. International Journal of Business and Administrative Studies, 4, 167-175.

Karjaluoto, H., Riquelme, H. E., \& Rios, R. E. (2010). The moderating effect of gender in the adoption of mobile banking. International Journal of bank marketing, 28(5), 328.

Koening, L. N., Marquet, M., Palmer, A., \& Zhao, A. L. (2015). Enjoyment and social influence: Predicting mobile payment adoption. The Service Industries Journal, 35(10), 537-554.

Labaree, R. V. (2009). Research guides: Organizing your social sciences research paper: Qualitative methods. Retrieved from: https://www.afidep.org/wpcontent/uploads/2016/08/Module-3-Handout-1-1 2-Ma jor-Types-of-ResearchDesigns.pdf

Lim, C. Y. (2018). Pushing wider adoption of eWallet. Retrieved from http://www.focusmalaysia.my/Mainstream/pushing-wider-adoption-ofe-wallet

Liu, G. S., \& Tai, P. T. (2016). A study of factors affecting the intention to use mobile payment services in Vietnam. Economics, 4(6), 249-273.

Liu, S., Zhuo, Y., Soman, D., \& Zhao, M. (2012). The consumer implications of the use of electronic and mobile payment systems. Rotman School of Management, University of Toronto.

Lu, J., Yao, J. E., \& Yu, C. S. (2005). Personal innovativeness, social influences and adoption of wireless internet services via mobile technology. The Journal of Strategic Information Systems, 14(3), 245-268.

Lwoga, E. T., \& Lwoga, N. B. (2017). User acceptance of mobile payment: The effects of usercentric security, system characteristics and gender. The Electronic Journal of Information Systems in Developing Countries, 81(1), 1-24. 
Madan, K., \& Yadav, R. (2016). Behavioural intention to adopt mobile wallet: A developing country perspective. Journal of Indian Business Research, 8(3), 227244. https://doi.org/10.1108/JIBR-10-2015-0112

Manikandan, S., \& Jayakodi, J. M. (2017). An empirical study on consumer adoption of mobile wallet with special reference to Chennai city. International Journal of ResearchGranthalaya, 5(5), 107-115.

Mehrad, D., \& Mohammadi, S. (2017). Word of mouth impact on the adoption of mobile banking in Iran. Telematics and Informatics, 34(7), 1351-1363.

Murthy, S. R., \& Mani, M. (2013). Discerning rejection of technology. Sage Open, 3(2), 1-10.

Mun, Y., Khalid, H., \& Nadarajah, D. (2017). Millennials' perception on mobile payment services in Malaysia. Procedia Computer Science, 124, 397-404.

Oliveira, T., Thomas, M., Baptista, G., \& Campos, F. (2016). Mobile payment: Understanding the determinants of customer adoption and intention to recommend the technology. Computers in Human Behavior, 61, 404-414.

Olsen, M., Hedman, J., \& Vatrapu, R. (2012). Designing digital payment artifacts. In Proceedings of the 14th Annual International Conference on Electronic Commerce, 161168.

Pal, D., Vanijja, V., \& Papasratorn, B. (2015). An empirical analysis towards the adoption of NFC mobile payment system by the end user. Procedia Computer Science, 69, 13-25.

Patel, V. (2016). Use of Mobile wallet service by the youth: A study based in Ahmedabad. ASBM Journal of Management, 9(2), 50.

Rai, N., Ashok, A., Chakraborty, J., Arolker, P., \& Gajera, S. (2012). M-wallet: An SMS based payment system. International Journal of Engineering Research and Applications, 258263.

Rogers, E. M. (1995). Diffusion of Innovations (4th edition). New York: Free Press

Roy, S., \& Sinha, I. (2017). Factors affecting customers' adoption of electronic payment: An empirical analysis. Journal of Business and Management, 19(12), 76-90.

Sarika, P. \& Vasantha, S. (2019). Impact of mobile wallets on cashless transaction. International Journal of Recent Technology and Engineering, 7, 1164-1171.

Saxena, S., Vyas, S., Kumar, B. S., \& Gupta, S. (2019). Survey on online electronic payments security. In 2019 Amity International Conference on Artificial Intelligence (AICAI), 756751. IEEE.

Shankar, A., \& Datta, B. (2018). Factors Affecting Mobile Payment Adoption Intention: An Indian Perspective. Global Business Review, 19, S72-S89.

Seetharaman, A., Kumar, K. N., Palaniappan, S., \& Weber, G. (2017). Factors influencing behavioural intention to use the mobile wallet in Singapore. Journal of Applied Economics \& Business Research, 7(2), 116-136.

Shin, D. H. (2009). Towards an understanding of the consumer acceptance of mobile wallet. Computers in Human Behavior, 25(6), 1343-1354.

Sidek, N. (2015). Determinants of electronic payment adoption in Malaysia: The stakeholders' perspectives. Retrieved from https://core.ac.uk/download/pdf/43372344.pdf

Suh, B., \& Han, I. (2003). The impact of customer trust and perception of security control on the acceptance of electronic commerce. International Journal of Electronic Commerce, 7(3), 135-161.

Sunny, P., \& George, A. (2018). Determinants of behavioral intention to use mobile wallets-A conceptual model. Journal of Management (JOM), 5(5), 52-62. 
Taheam, K., Sharma, R., \& Goswami, S. (2016). Drivers of digital wallet usage: Implications for leveraging digital marketing. International Journal of Economic Research, 13(1), 175186.

Tan, Y., \& Cheong, Y. L. (2018). Banking on the eWallet in Malaysia. Retrieved from https://www.pwc.com/my/en/assets/blog/pwc-my-deals-strategy-banking-ontheewallet-in-malaysia.pdf

Tavilla, E. (2012). Opportunities and challenges to broad acceptance of mobile payments in the United States. Federal Reserve Bank of Boston.

Teng, P. K., Ling, T. J., \& Seng, K. W. K. (2018). Understanding customer intention to use mobile payment services in Nanjing, China. International Journal of Community Development and Management Studies, 2, 49-60. Retrieved from http://ijcdms.org/Volume02/v2p049060Teng4446.pdf

Teo, T. S., \& Ranganathan, C. (2004). Adopters and non-adopters of business-to-business electronic commerce in Singapore. Information Management, 42(1), 89-102.

Teoh, M. Y., Chong, W. C., S., Lin, S. B., \& Chua, W. J. (2013). Factors affecting consumers' perception of electronic payment: An empirical analysis. Internet Research, 23(4), 465485.

The Nielson Company. (2019). Cash or cashless? Malaysia's shifting payment landscape. Retrieved from https://www.nielsen.com/my/en/insights/reports/2019/cash-orcashless-mala ysias -shifting-payment-landscape.html

Trivedi, J. (2016). Factors determining the acceptance of EWallets. International Journal of Applied Marketing and Management, 1(2), 42-53.

Toh, T. W., Marthandan, G., Chong, A. Y. L., Ooi, K. B., \& Arumugam, S. (2009). What drives Malaysian m-commerce adoption? An empirical analysis. Industrial Management and Data Systems, 109(3), 370-388.

Tu, N. V. (2019). Factors influencing consumers' intention to adopt mobile wallet in Ho Chi Minh city. Retrieved from https://pdfs.semanticscholar.org/8cc3/7c8860bc5623a61b2fbe77dedacc8f23e ba7.pdf

Varsha, R., \& Thulasiram, M. (2016). Acceptance of eWallet services: A study of consumer behavior. International Journal of Innovative Research in Management Studies, 1(4), 2455-7188.

Venkatesh, V., \& Davis, F. (2000). A theoretical extension of the technology acceptance model: Four longitudinal field studies. Management Science, 46(2), 186-204.

Venkatesh, V., Morris, M. G., Davis, G. B., \& Davis, F. D. (2003). User acceptance of information technology: Toward a unified view. MIS Quarterly:Management Information Systems, 27(3), 425-478.

Venkatesh, V., Thong, J. Y., \& Xu, X. (2012). Consumer acceptance and use of information technology: Extending the unified theory of acceptance and use of technology. MIS Quarterly, 36(1), 157-178.

Wong, W. H., \& Mo, W. Y. (2019). A study of consumer intention of mobile payment in Hong Kong, based on perceived risk, perceived trust, perceived security and technological acceptance model. Journal of Advanced Management Science, 7, 33-38.

Wright, S., O'Brien, B. C., Nimmon, L., Law, M., \& Mylopoulos, M. (2016). Research design considerations. Journal of Graduate Medical Education, 8(1), 97-98.

Yang, M., Mamun, A. A., Mohiuddin, M., Nawi, N. C., \& Zainol, N. R. (2021). Cashless transactions: A study on intention and adoption of eWallets. Sustainability, 13, 831. https://doi.org/10.3390/su13020831 
INTERNATIONAL JOURNAL OF ACADEMIC RESEARCH IN BUSINESS AND SOCIAL SCIENCES Vol. 11, No. 11, 2021, E-ISSN: 2222-6990 @ 2021 HRMARS

Yapp, E. (2018). A year on, Axiata digital tags on mobile wallet to boost app. Retrieved from https://www.digitalnewsasia.com/business/year-axiata-digital-tagsmobilewallet 